\title{
Revistas científicas y blogs académicos: la sinergia perfecta
}

\author{
Luis A. Gorordo-Delsol, ${ }^{1,2 *}$ y Silvia E. Uribe-Moya ${ }^{3}$ \\ ${ }^{1}$ Unidad de Cuidados Intensivos de Adultos, Hospital Juárez de México; ${ }^{2}$ Editor jefe, Revista de Educación en Investigación en Emergencias, \\ Sociedad Mexicana de Medicina de Emergencia A.C.; ${ }^{3}$ Servicio de Urgencias, Hospital Español de México. Ciudad de México, México
}

\begin{abstract}
Resumen
Las revistas científicas y los blogs académicos parecen crecer en comunión, en las primeras se publican los artículos, en los segundos se discuten de forma más coloquial; los blogs son herramientas didácticas que pueden ser utilizadas por estudiantes, docentes e investigadores como primeros pasos hacia la publicación de artículos más serios y técnicos en revistas, mientras que los artículos de actualidad pueden ser desmenuzados en los blogs por los mismos autores como un ejercicio de difusión y discusión abierta con los lectores, esto crea redes de conocimiento que hacen crecer a las ciencias, incluida la medicina de urgencias.
\end{abstract}

Palabras clave: Medicina de emergencia. Investigación. Revistas. Blogs.

\section{Scientific journals and academic blogs: the perfect synergy}

\section{Abstract}

Scientific journals and academic blogs seem to grow in communion, in the first ones articles are published, in the other they are discussed in a more colloquial way; Blogs are didactic tools that can be used by students, teachers and researchers as first steps towards the publication of more serious and technical articles in journals, while current articles can be shredded into blogs by the authors themselves as an exercise in dissemination and open discussion with readers, this creates knowledge networks that make science grow, including Emergency Medicine.

Key words: Emergency medicine. Research. Journals. Blogs.

Parece innegable que las revistas científicas impresas están desapareciendo, los sitios web y los archivos PDF (siglas en inglés de Portable Document Format, formato de documento portátil) han desplazado al papel, las tecnologías de la información permiten la digitalización, almacenaje, transmisión (léase desde una consulta en un buscador, pasando por un correo electrónico hasta las redes sociales como
Facebook, Twitter y WhatsApp) y manipulación de miles de revistas digitales y sus millones de artículos, como se logra en la Revista de Educación e Investigación en Emergencias (REIE). Las ciencias de la salud no están exentas de este fenómeno; a la par de la digitalización de las revistas científicas, nacen otras plataformas de expresión y discusión escrita: los blogs académicos ${ }^{1}$.

\section{Correspondencia:}

*Luis A. Gorordo-Delsol

E-mail: luis.gorordodelsol@icloud.com
Disponible en internet: 13-09-2021

Fecha de recepción: 26-07-2021

Fecha de aceptación: 30-07-2021

DOI: 10.24875/REIE.M21000013
Rev Educ Investig Emer. 2021;3(3):159-161 www.medicinadeemergencias.com

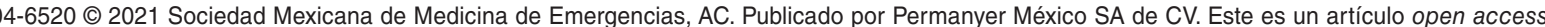
bajo la licencia CC BY-NC-ND (http://creativecommons.org/licenses/by-nc-nd/4.0/). 
Tabla 1. Comparación de características entre revistas científicas y blogs académicos

\begin{tabular}{|c|c|c|}
\hline Característica & Revistas & Blogs \\
\hline Valor curricular & $\mathrm{Si}^{*}$ & Poco o nulo \\
\hline $\begin{array}{l}\text { Instrucciones para } \\
\text { autores }\end{array}$ & $\begin{array}{l}\text { Estándares } \\
\text { internacionales }\end{array}$ & Reglas propias \\
\hline Lenguaje & Técnico & Técnico o coloquial \\
\hline $\begin{array}{l}\text { Recepción de } \\
\text { manuscritos }\end{array}$ & Continua & Continua \\
\hline Revisión por pares & Mayoría & Minoría \\
\hline $\begin{array}{l}\text { Tiempo para } \\
\text { publicación }\end{array}$ & 1 a 12 meses & Continua \\
\hline Discusión & Cartas al editor & $\begin{array}{l}\text { Chats de acceso } \\
\text { abierto }\end{array}$ \\
\hline Citable & Sí & $\mathrm{Si}^{\dagger}$ \\
\hline Trazabilidad & Robusta & De nula a poca \\
\hline Almacenaje & $\begin{array}{l}\text { De plazos largos a } \\
\text { permanente }\end{array}$ & Indefinido \\
\hline Acceso & Suscripción o libre & Libre \\
\hline Extensión & Mayor & Menor \\
\hline $\begin{array}{l}\text { Referencias } \\
\text { bibliográficas }\end{array}$ & Sí & Sí \\
\hline Impresión & Opcional & No \\
\hline Control y regulación & Sí & Sí \\
\hline
\end{tabular}

Los blogs (como EMergiendo.org) son espacios difusión y discusión académica que permiten una rápida publicación de revisiones cortas de artículos originales, revisiones bibliográficas, notas de opinión, casos e imágenes en un formato más flexible ${ }^{1-3}$, y son publicados por sociedades científicas, universidades, grupos de residentes o de forma independiente. Shema, et al. analizaron una serie de blogs y encontraron que, entre los bloggers (autores de los blogs) aproximadamente el $49 \%$ tiene posgrados y el resto son estudiantes en pregrado o posgrado ${ }^{2}$, por lo que estas plataformas llegan a ser muy profesionales y especializadas, lo que da profundidad al debate. Esto motiva a los investigadores noveles a leer, criticar, escribir y publicar'.

Las comunidades científicas (y los investigadores) se pueden beneficiar de los blogs, donde un artículo se puede discutir y desmenuzar de una forma más coloquial e informal, los lectores pueden hacer comentarios críticos y preguntas directas a los bloggers y recibir retroalimentación, funcionan como colectores de ideas para crear o afinar nuevos protocolos y finalmente como comunidad científica que crea redes de conocimiento entre investigadores y lectores ${ }^{2,3,5}$. Además de lo anterior, los artículos originales de revistas científicas que son discutidos en blogs son mejor comprendidos por los estudiantes, y los blogs dan más visibilidad al trabajo, lo que se asocia a más citaciones para un artículo de revista a mediano plazo $0^{6,7}$, esto beneficia al artículo (más citaciones), al autor (mayor índice H) y a las revistas (mejor factor de impacto).

Los blogs han cobrado un papel importante en las ciencias de la salud, al igual que las revistas, con la finalidad de otorgar otra herramienta de aprendizaje y generación de pensamiento crítico ${ }^{3}$. Sin duda, compartir información en blogs formará parte de la discusión científica en un futuro no muy lejano ${ }^{2}$, la sinergia entre revistas y blogs se fortalecerá conforme los editores de ambas partes puedan encontrar los mecanismos para trabajar juntos, los blogs como semilleros de investigadores y herramientas de discusión, y las revistas como editoras, publicadoras y promotoras de contenidos científicos de calidad. Próximamente la REIE y EMergiendo lanzarán trabajos conjuntos que permitan a los lectores interacción entre artículos, blog, vídeo y, por supuesto, con los autores. La REIE y EMergiendo, ambas de la Sociedad Mexicana de Medicina de Emergencia A.C., se complementan para el crecimiento y desarrollo de la medicina de urgencias en beneficio de los profesionales de la salud y pacientes que día a día son atendidos en las salas de urgencias.

\section{Financiamiento}

El presente trabajo no ha recibido ninguna beca específica de agencias de los sectores públicos, comercial o sin ánimo de lucro.

\section{Conflicto de intereses}

Los autores declaran no tener conflicto de intereses relacionados con este trabajo.

\section{Responsabilidades éticas}

Protección de personas y animales. Los autores declaran que para esta investigación no se han realizado experimentos en seres humanos ni en animales.

Confidencialidad de los datos. Los autores declaran que en este artículo no aparecen datos de pacientes. 
Derecho a la privacidad y consentimiento informado. Los autores declaran que en este artículo no aparecen datos de pacientes.

\section{Bibliografía}

1. Sociedad Mexicana de Medicina de Emergencia A.C. [sede Web] Ciudad de México: Comité Editorial EMergiendo; 2020 [actualizada: junio 2021; acceso: 8 de julio de 2021]. Disponible en: www.emergiendo.org.

2. Shema H, Bar-llan J, Thelwall M. Research blogs and the discussion of scholarly information. PLoS One. 2012;7:e35869.
3. Conde-Caballero D, Castillo CA, Ballesteros-Yéñez I, Mariano-Juárez L. Blogging as a tool for the acquisition and dissemination of knowledge in health sciences: a preliminary evaluation. International Journal of Educational Technology in Higher Education; 2019;16:1-5.

4. Rivas-Ruiz R, Roy-García IA, Pérez-Rodríguez M, Moreno-Noquez M, Flores-Pulido A, Jiménez-Martínez MC, et al. \#Publica \#IniciativaM: publica mejor. Rev Educ Investigadores Emer; 2021; 3 (2): 100-104.

5. Cameron CB, Nair V, Varma M, Adams M, Jhaveri KD, Sparks MA. Does academic blogging enhance promotion and tenure? A survey of US and Canadian medicine and pediatric department chairs. JMIR Med Educ. 2016;2:e10.

6. British Medical Journals [sede Web]. Londres: BMJ Group blogs; 2021 [actualizada: junio de 2021, acceso: 8 de julio de 2021]. Disponible en: https://blogs.bmj.com.

7. Eysenbach G. Can tweets predict citations? Metrics of social impact based on Twitter and correlation with traditional metrics of scientific impact. J Med Internet Res. 2011;13:e123. 